\title{
Optimized Dispatch Schedule for Autonomous Grids in Isolated Islands
}

\author{
Liuyang FAN ${ }^{1}$, Keyou WANG ${ }^{1}$ and Wenhui $\mathrm{SHI}^{2}$ \\ ${ }^{1}$ Key Laboratory of Control of Power Transmission and Conversion, Ministry of Education, Department of Electrical Engineering, Shanghai \\ Jiao Tong University, Shanghai, China; \\ ${ }_{2}^{2}$ State Grid Electric Power Research Institute, Beijing, China
}

\begin{abstract}
The rapid development of wind power provides a new solution for power supply of isolated island. However, due to the intermittent and stochastic nature of renewable energy resources (RES), the energy storage unit (ESU) is required for power grid reliability. This paper proposed an automatic programming method for autonomous grid in isolated islands. The sea water pumped storage plant serves as ESU to counter-balance the fluctuations of RESs. The penetration level of RES and the profit of the Island system operator (ISO) increase significantly. With the geographical and historical data of an island in China, the effectiveness of the proposed method is testified.
\end{abstract}

\section{Introduction}

The conventional power supply solution of isolated island is diesel units. This type of generators consume heavy oil, which is not only expensive but also pollutional. Recent years, the renewable energy resources (RESs) have provided a new and promising solution for power generation in isolated islands. $[1,2]$ However, RESs is not stable[3]. The output of RESs is stochastic and intermittent.[4] In an autonomous grid, which lacks of spinning reserve capacity, the energy storage unit (ESU) is needed to stabilize the output of RESs and secures the reliability of power supply.[6,8] Whereas for small islands (less than $1 \mathrm{MW}$ ), Battery energy storage systems (BESS) seem to be the viable choice[5], pumped storage plants, as the most technically mature solution, are suitable for large and medium islands with appropriate geographical conditions.[7]

The introduction of joint operation of pumped storage plant and wind farm has been discussed in several publications.[9-15] However, in the current researches, there are no studies specific to the pumped storage plant operating in islands. In an autonomous island, the reserve capacity is far less than that in mainland. The lack of reserve capacity will impair the ability to remain power balance when the RES output fluctuates. If the Island System Operator (ISO) wants an autonomous gird working in high RES penetration level, the dispatch schedule must be viable and robust, which not only consume as much RES output as possible, but also guarantee power balance when RES output fluctuates.

In this paper, an automatic programming method for the joint operation schedule of pumped storage plant and wind farm is proposed. Based on the day ahead predictions of the wind farm production, the programming method generates the optimized operation schedule and achieves the minimum cost. Meanwhile, the water level limitations, spinning reserve limitations and power balance will be secured. Based on the historical data of the output of the wind farm, several typical scenarios are calculated and the effectiveness of the proposed programming method is verified.

\section{Autonomous Grid in Island}

Figure 1 shows the system configuration of the grid. It includes a wind farm, a pumped storage plant, a diesel unit and the load. The wind farm represent RESs with uncertainty. It can also be replaced by solar or other form of RESs. The pumped storage plant works in two operational modes depend on the wind farm production and power consumption of load. If the pumped storage plant works as a hydraulic turbine, it releases water of upper reservoir and generates power. If the pumped storage plant works as a pump, it absorbs power and draw water from the ocean. In this way, the pumped storage plant stabilizes the stochastic output of wind farm. The DU is a controllable power source and compensates the margin between wind farm production and load demand.

The typical dispatch operates as the following steps: Step 1: The wind farm reports the forecasting of production in the next 24 hours based on the weather, temperature, etc.

Step 2: The dispatch centre collects the reported productions from the wind farm and forecasts the power load curve in the next 24 hours.

Step 3: Based on the both predicted data, the dispatch centre calculated the optimized operation schedules of the 
pumped storage plant, diesel units and wind farm, according to the proposed programming method.

Step 4: The wind farm, diesel units and pumped storage plant carry out the operation scheduled and the fluctuations will be compensate by diesel units.

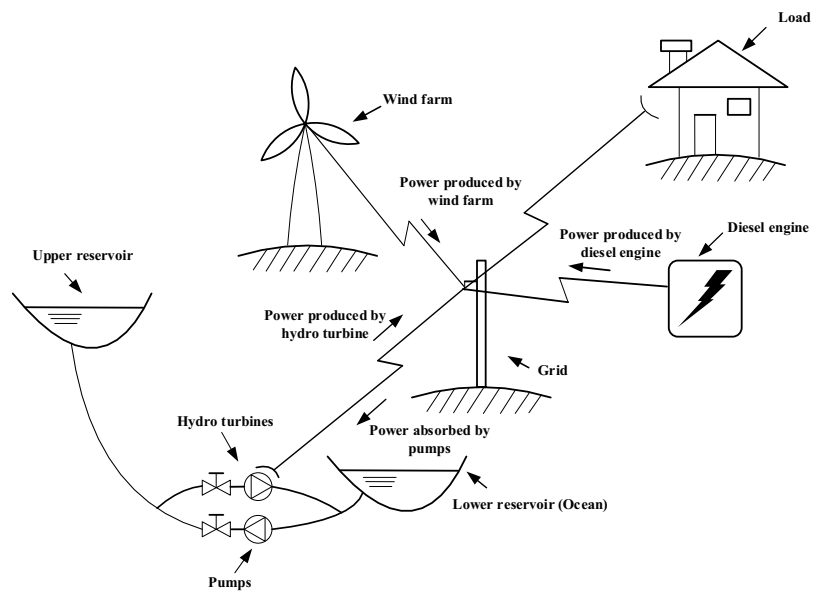

Figure 1. The schematic layout of an autonomous grid in islands

\section{The Optimized Dispatch Schedule}

\subsection{Optimization Target}

The optimization target of the dispatch centre is to achieve the minimum cost of power generation. RESs, such as wind power, solar, usually cost far less than diesel units. Therefore, the power grid should consume as much power of RESs as possible. The start up and shut down cost of the diesel units are very small, which can be ignored in the day ahead schedule.

Considering the rapid fluctuations of the RESs, the day ahead dispatch schedule is calculated in step of every 15 minutes.

$$
\begin{aligned}
f_{c}=\max \sum_{i=1}^{96} & {\left[\lambda_{i}\left(W_{i}+T_{i}+D_{i}-P_{i}\right)-C_{s u} P_{i}^{s u}\right.} \\
& \left.-C_{s d} P_{i}^{s d}-\rho D_{i}\right]
\end{aligned}
$$

where, $f_{c}$ represents the total profit of the ISO in a day; $W_{i}$ represents the output of the wind farm in period $i ; T_{i}$ represents the produced power when the pumped storage plant working as a hydraulic turbine in period $i$; $P_{i}$ represents the absorbed power when the pumped storage plant working as a pump in period $i ; D_{i}$ represents the output of the diesel units in period $i$; $\lambda_{i}$ represents the electrical market price in period $i$; $C_{s u}$ and $C_{s d}$ represent the start up and shut down cost of a pump unit; $P_{i}^{s u}$ and $P_{i}^{s d}$ represent the number of the pumps which start up or shut down in the period $i ; \rho$ represents the fuel cost of a diesel unit.

\subsection{Constraints}

The production of the wind farm is mainly affected by wind speed at that time. Adjusting the pitch angle of the wind turbine, the output of wind farm can be reduced.

$$
\begin{gathered}
0 \leq W_{i} \leq \bar{W} \\
0 \leq W_{i} \leq W_{i}^{f}
\end{gathered}
$$

where, $\bar{W}$ represents the installed capacity of the wind farm; $W_{i}^{f}$ represents the maximum production of the wind farm in period $i$;

The operation of the pumped storage plant is bounded by the geographical conditions. The output is related to the water level of the upper reservoir. To ensure the regulating ability, the water level of the upper reservoir must remain in a certain range. The pump storage plant in an island uses ocean as the lower reservoir. The water level variations are much smaller than the traditional pumped storage plant, which is very convenient for the design of hydraulic turbine.

$$
\begin{gathered}
H_{i}=H_{i-1}+\frac{P_{i-1} \cdot \Delta t \cdot \eta_{P}}{\rho_{w} \cdot g \cdot \hat{H} \cdot S}-\frac{T_{i-1} \cdot \Delta t}{\rho_{w} \cdot g \cdot \hat{H} \cdot S \cdot \eta_{T}} \\
H_{\min } \leq H_{i} \leq H_{\max }, \forall i \in\{1,2, \cdots, 96\} \\
\left|H_{0}-H_{96}\right| \leq \delta\left(H_{\text {max }}-H_{\text {min }}\right)
\end{gathered}
$$

where, the $H_{i}$ represents the water level of the upper reservoir in the period; $\Delta t$ represents the duration of a period $i ; \eta_{P}$ represents the efficiency of pumped-storage plant when it works as a pump; $\eta_{T}$ Efficiency of pumped-storage plant when it works as a hydraulic turbine; $\rho_{w}$ represents the density of the sea water; $\hat{H}$ represents the effective height of the upper reservoir; $S$ represents the area of the upper reservoir; $\delta$ represents the maximum proportion of capacity variation of the upper reservoir.

Equation (4) specifies the relationship between the power production and the water level variation. The upper reservoir is simplified as a stylidium, otherwise the constraints will be nonlinear and unable to solve. Equation (5) signifies that the water level must remain in a certain range at all time. Equation (6) signifies that the water level variation in a day should not exceed the maximum proportion, otherwise the regulating ability will be jeopardized.

$$
\begin{gathered}
0 \leq P_{i}^{o n} \leq\left(1-f_{i}^{T}\right) \cdot N \\
0 \leq T_{i}^{o n} \leq f_{i}^{T} \cdot N \\
0 \leq P_{i}^{s u} \leq\left(1-f_{i}^{T}\right) \cdot N \\
P_{i}^{s u} \leq N-P_{i-1}^{o n} \\
P_{i}^{s d} \leq P_{i-1}^{o n} \\
P_{i}^{o n}=\sum_{k=1}^{i}\left(P_{k}^{s u}-P_{k}^{s d}\right) \\
P_{i}^{o n} \cdot P_{\min } \leq P_{i} \leq P_{i}^{o n} \cdot P_{\max } \\
T_{i}^{o n} \cdot T_{\min } \leq T_{i} \leq T_{i}^{o n} \cdot T_{\max }
\end{gathered}
$$

where, $N$ represents the total number of the hydraulic turbines; $P_{i}^{\text {on }}$ represents the number of operating pumps in period $i ; T_{i}^{o n}$ represents the number of operating hydraulic turbines in period $i ; P_{i}^{s u}$ represents the number of hydraulic turbines which start up in period 
$i ; P_{i}^{s d}$ represents the number of hydraulic turbines which start up in period $i ; f_{i}^{T}$ is a binary variable which represents whether the pumped storage plant can work as a hydraulic turbine or not in period $i ; P_{\min }$ and $P_{\max }$ represent the input power limits when pumped-storage plant works as a pump; $T_{\min }$ and $T_{\max }$ represent the generation power limits when pumped-storage plant works as a hydro turbine.

Equation (7) and (8) signify the boundary of the operating pumps or turbines. The pumped storage plant should not draw and release water at the same time. The common efficiency of a pumped storage plant is about $75 \%$ percent. To generate and absorb power at the same time will waste electricity. In some researches, this constraint is expressed as follows:

$$
\sum_{i=1}^{96}\left(P_{i}^{o n} \cdot T_{i}^{o n}\right) \leq 0
$$

Equation (15) equivalents Equation (7) and (8), and seems more elegant. However, a quadratic constraints would complicate the problem and significantly exacerbates the calculation burden. In this paper, a binary variable $f_{i}^{T}$ is added to ensure the pumped storage plant would not generate and absorb power at the same time.

$$
\begin{gathered}
D_{i}=L_{i}+P_{i}-T_{i}-W_{i} \\
0 \leq D_{i} \leq \bar{D}-D_{r}
\end{gathered}
$$

where, $D_{i}$ represents the output of the diesel unit in period $i ; L_{i}$ represents the power load of the island in period $i ; \bar{D}$ represents the installed capacity of the diesel units; $D_{r}$ represents the capacity of diesel units serving as the spinning reserve.

Equation (16) indicates that the diesel units compensate the mismatch between power demand and power production of RESs. Equation (17) ensures that there is enough reserve to deal with the fluctuations of RESs.

\section{Case Study}

At present, there are no pumped seawater hydro storage (PSHS) in China. The only PSHS is the one in Okinawa, Japan. In this paper, we presume a pumped storage plant is built in Nanji Island, China, and solve the problem with YALMIP [16] and IBM ILOG Cplex to verify the validity of the proposed method.

Nanji Island is far away from the mainland and not inter-connected. The power supply of the island is covered by diesel units. In the year 2012, a testing project of micro grid is built in this island. The power demand of the island is estimated to be $2 \mathrm{MW}$ in the year 2016. The daily power load curve and output forecasting curve is show in Figure 2.

According to the proposed programming method, the optimal operating schedules for pumped storage plant and diesel units are shown in Figure 3 and Figure 4. The variations of water level of the upper reservoir is shown in Figure 5.
Table 1. The parameters of power grid in offshore island

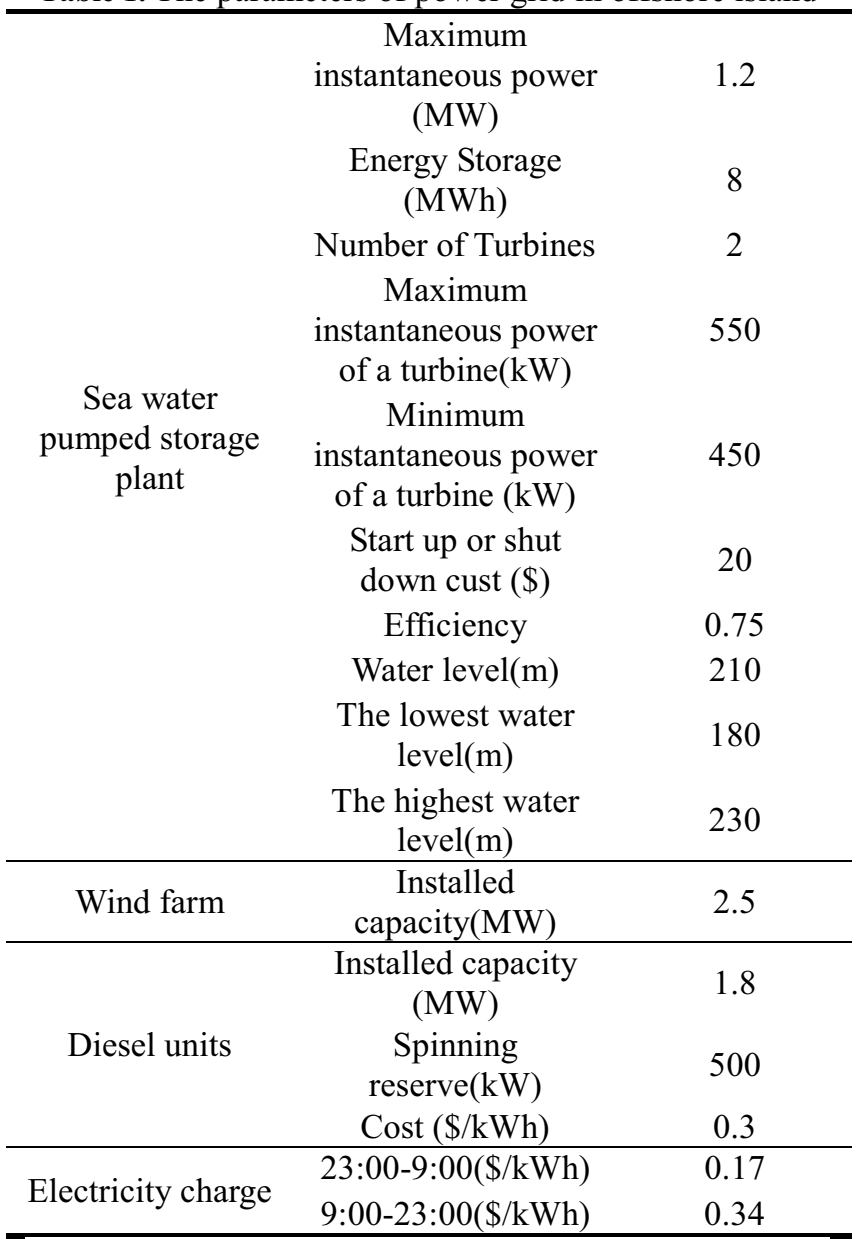

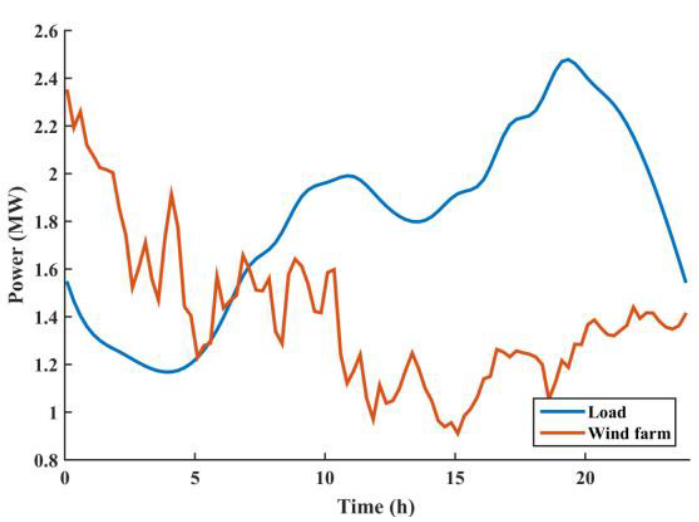

Figure 2. Daily load curve and output of wind farm

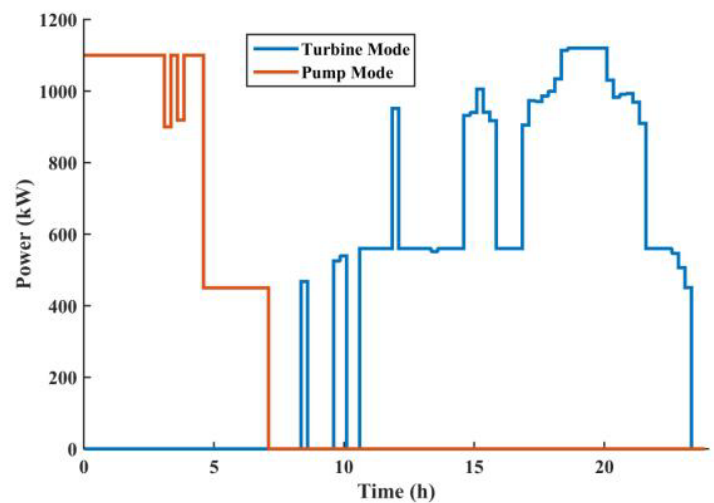

Figure 3. The output curve of HSPS in pump mode and turbine mode 


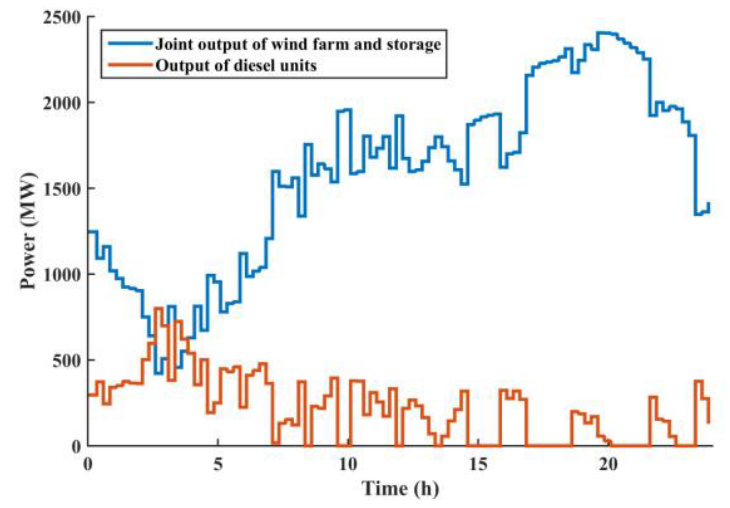

Figure 4. The output curve of wind-storage joint system

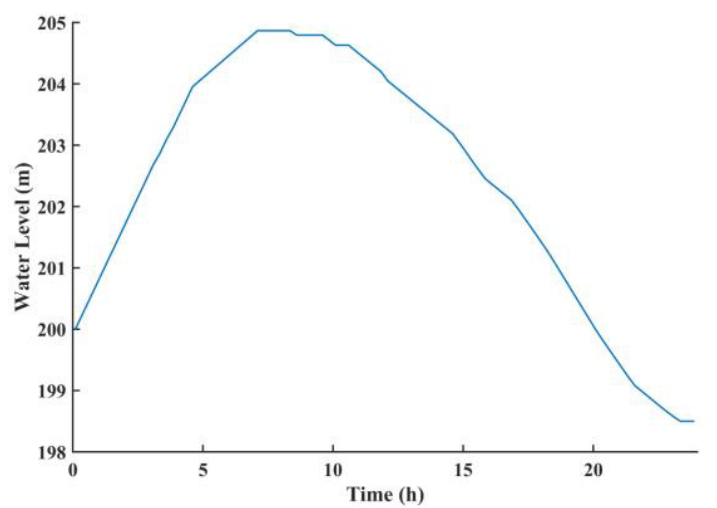

Figure 5. The variations of the water level of upper reservoir

As we can see in this case, the wind farm replaces the diesel units as the main generator. The cost of electricity is much smaller. However, the output of the wind farm is highly random and stochastic, this programming method must be testified under various circumstances. Based on the historical data of wind speed, several typical scenarios of wind farm are shown in Figure 6.

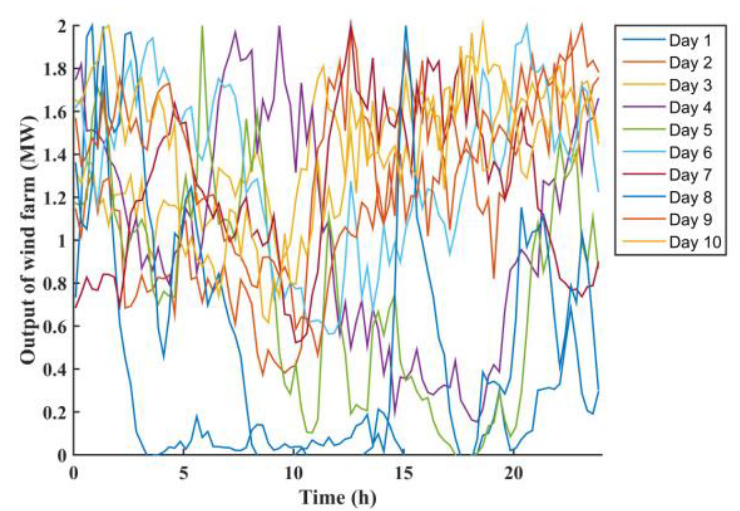

Figure 6. The wind power output in multiple typical scenarios

The profit of the typical scenarios is shown in Table 2 . In various different scenarios, the programming method is proved to be effective. The profit with HSPS is significantly higher than without HSPS. With the energy storage unit, the penetration level of RESs increases and the cost of diesel units is much smaller.
Table 2 The profits in typical scenarios

\begin{tabular}{|c|c|c|c|c|c|c|}
\hline \multirow[b]{2}{*}{ No. } & \multirow[b]{2}{*}{$\begin{array}{c}\text { Electri } \\
\text { cy } \\
\text { charge } \\
(\$)\end{array}$} & \multicolumn{2}{|c|}{ Without HSPS } & \multicolumn{3}{|c|}{ With HSPS } \\
\hline & & $\begin{array}{l}\text { cost } \\
\text { of } \\
\text { diesel } \\
\text { units } \\
(\$)\end{array}$ & $\begin{array}{l}\text { Profit } \\
(\$)\end{array}$ & $\begin{array}{c}\text { Start } \\
\text { up of } \\
\text { shut } \\
\text { down } \\
\text { cost } \\
(\$)\end{array}$ & $\begin{array}{c}\text { cost of } \\
\text { diesel } \\
\text { units } \\
(\$)\end{array}$ & $\begin{array}{l}\text { Profit } \\
(\$)\end{array}$ \\
\hline 1 & 12313 & 10301 & 2012 & 160 & 7795 & 4358 \\
\hline 2 & 12490 & 4051 & 8439 & 100 & 2855 & 9535 \\
\hline 3 & 12378 & 2364 & 10014 & 140 & 1557 & 10682 \\
\hline 4 & 12211 & 5028 & 7182 & 100 & 3300 & 8811 \\
\hline 5 & 12312 & 6822 & 5490 & 120 & 4760 & 7432 \\
\hline 6 & 12326 & 3646 & 8680 & 80 & 1831 & 10415 \\
\hline 7 & 12410 & 3871 & 8539 & 120 & 2475 & 9815 \\
\hline 8 & 12346 & 7655 & 4692 & 200 & 5138 & 7008 \\
\hline 9 & 12356 & 3618 & 8738 & 100 & 1897 & 10359 \\
\hline 10 & 12451 & 3313 & 9138 & 80 & 1715 & 10656 \\
\hline
\end{tabular}

\section{Conclusion}

This paper proposes an automatic programming method for optimal dispatch of autonomous grid in isolated islands. The pumped storage plant is applied as the energy storage system to counter-balance the fluctuations of the RESs. The penetration level of the RESs increases significantly, and the production of diesel units is much smaller. Meanwhile, with diesel unit serving as the spinning reserve, the reliability of the autonomous grid is not jeopardized. The proposed programming method is suitable for isolated islands with the potential of RES and geographical advantage of pumped storage plant. To improve the robustness of the programming method is the next step of our research.

\section{Acknowledgment}

This work is sponsored by National High Technology Research and Development Program of China under Grant No. 2014AA052003.

\section{References}

1. J. Anagnostopoulos and D. Papantonis, "Simulation and size optimization of a pumped-storage power plant for the recovery of wind-farms rejected energy," Renewable Energy, vol. 33, pp. 1685-1694, 2008.

2. C. Bueno and J. A. Carta, "Wind powered pumped hydro storage systems, a means of increasing the penetration of renewable energy in the Canary Islands," Renewable and Sustainable Energy Reviews, vol. 10, pp. 312-340, 2006.

3. D. Liu, D. Niu, H. Wang, and L. Fan, "Short-term wind speed forecasting using wavelet transform and support vector machines optimized by genetic algorithm," Renewable Energy, vol. 62, pp. 592-597, 2014.

4. H. Holttinen, P. Meibom, A. Orths, B. Lange, M. O'Malley, J. O. Tande, et al., "Impacts of large amounts of wind power on design and operation of 
power systems, results of IEA collaboration," Wind Energy, vol. 14, pp. 179-192, 2011.

5. H. Ibrahim, A. Ilinca, and J. Perron, "Energy storage systems - characteristics and comparisons," Renewable and sustainable energy reviews, vol. 12, pp. 1221-1250, 2008.

6. E. Vrettos and S. Papathanassiou, "Operating policy and optimal sizing of a high penetration RES-BESS system for small isolated grids," Energy Conversion, IEEE Transactions on, vol. 26, pp. 744-756, 2011.

7. J. K. Kaldellis, K. Kavadias, and D. Zafirakis, "The role of hydrogen-based energy storage in the support of large-scale wind energy integration in island grids," International Journal of Sustainable Energy, vol. 34, pp. 188-201, 2015.

8. T. K. Brekken, A. Yokochi, A. Von Jouanne, Z. Z. Yen, H. M. Hapke, and D. Halamay, "Optimal energy storage sizing and control for wind power applications," Sustainable Energy, IEEE Transactions on, vol. 2, pp. 69-77, 2011.

9. J. S. Anagnostopoulos and D. E. Papantonis, "Study of pumped storage schemes to support high RES penetration in the electric power system of Greece," Energy, vol. 45, pp. 416-423, 2012.

10. F. P. Montero and J. J. Pérez, "Wind-hydro integration: pumped storage to support wind," Hydro Review Worldwide (HRW), 2009.

11. S. Papaefthimiou, E. Karamanou, S. Papathanassiou, and M. Papadopoulos, "Operating policies for wind- pumped storage hybrid power stations in island grids," IET Renewable Power Generation, vol. 3, pp. 293-307, 2009.

12. S. V. Papaefthymiou, E. G. Karamanou, S. Papathanassiou, and M. P. Papadopoulos, "A windhydro-pumped storage station leading to high RES penetration in the autonomous island system of Ikaria," Sustainable Energy, IEEE Transactions on, vol. 1, pp. 163-172, 2010.

13. S. A. Papathanassiou and N. G. Boulaxis, "Power limitations and energy yield evaluation for wind farms operating in island systems," Renewable Energy, vol. 31, pp. 457-479, 2006.

14. C. Zhao, J. Wang, J.-P. Watson, and Y. Guan, "Multi-stage robust unit commitment considering wind and demand response uncertainties," Power Systems, IEEE Transactions on, vol. 28, pp. 27082717, 2013.

15. J. Garcia-Gonzalez, D. la Muela, R. M. Ruiz, L. M. Santos, and A. M. González, "Stochastic joint optimization of wind generation and pumpedstorage units in an electricity market," Power Systems, IEEE Transactions on, vol. 23, pp. 460468, 2008.

16. J. Löfberg, "YALMIP: A toolbox for modeling and optimization in MATLAB," in Computer Aided Control Systems Design, 2004 IEEE International Symposium on, 2004, pp. 284-289. 